\title{
Is out of sight out of mind? The effects of resource cues on motivation in mink, Mustela vison
}

\author{
HARRIET WARBURTON \& GEORGIA MASON \\ Department of Zoology, University of Oxford \\ (Received 7 May 2002; initial acceptance 9 July 2002; \\ final acceptance 7 October 2002; MS. number: 7317)
}

\begin{abstract}
Measuring strength of preference is a powerful tool in welfare research. However, animals' preferences in so-called demand experiments may be influenced by stimuli from the test resources (e.g. olfactory or visual cues), leading to motivations different from those of the 'applied' animals who are not so exposed. Resource cues could act as eliciting stimuli, enhancing motivation, or they could supply information so that working for closer access to a resource becomes redundant. We assessed the priorities of mink in both a typical closed economy demand set-up (Cues, i.e. resource cues present when preference is expressed) and one where resource cues were distant and screened at the choice point (No Cues). Six mink were tested in both treatments, and their motivation to reach four resources (Food, Bath, Unpredictable Social Contact, Toy) was assessed via their responses to increased access costs (weighted doors). Of five measures, only the maximum price paid was unaffected by treatment. For the other four measures, cue availability affected the motivation to reach some resources but not others: there were significant treatment $\times$ resource effects on baseline visit rate, visit elasticity and consumer surplus, and a similar but nonsignificant trend for expenditure rate. The rank order of preferences was also affected by treatment: Food was most preferred in both treatments, but motivation for Toys and possibly also Unpredictable Social Contact declined in the No Cues treatment. This result has implications for the mink welfare debate and also for the design of valid preference experiments. We suggest that different designs and measures of motivation vary in their suitability for addressing the two types of applied questions that use motivational data.
\end{abstract}

(C) 2003 Published by Elsevier Science Ltd on behalf of The Association for the Study of Animal Behaviour.

Measuring behavioural preference is an important tool in animal welfare research (e.g. Mendl 2001), as well as in fundamental research into, for example, mate choice (e.g. Bateson 1980; Petrie et al. 1991) and diet selection (e.g. Arnold 1981; Rowland et al. 1995). The costs that animals are prepared to pay to gain access to resources allow the objective measurement of the strength of such preferences, which can be quantified with techniques from microeconomics, experimental psychology and behavioural ecology (e.g. Dawkins 1983; Mason et al. 2001). In animal welfare research, strength of preference is used to assess the importance of activities or resources that might improve farm, laboratory or zoo conditions, because motivation is inherently linked to feelings of pleasure and aversion (Cabanac 1971, 1979; Dawkins 1990; Rolls 1999). By quantifying animals' decisions we can assess the affective states accompanying the use of a range of resources. Such information is typically then used to inform two complementary, although different, applied

Correspondence: H. Warburton, Department of Zoology, University of Oxford, South Parks Road, Oxford, OX1 3PS, U.K. (email: harriet.warburton@zoology.oxford.ac.uk). questions. (1) What resources or activities do animals 'miss' in captivity? (2) What resources or activities would best improve welfare, if added to a cage or enclosure?

\section{The Problem of Resource Cues}

How a preference test is conducted potentially affects its outcome (Mason et al. 1998; Warburton \& Nicol 1998, 2001). However, one possibly important aspect of experimental design has been overlooked, that visual, olfactory and auditory stimuli from the test resources may impinge on the subject when in its home cage, when making choices, or both. Such resource cues may affect the subject's preferences in two ways, either by acting as eliciting stimuli that increase motivation to gain access to the resources (Forkman \& Haskell 1999) or by supplying information about resources, which then makes working for closer contact less important.

Examples of the eliciting influence that resource stimuli can have on motivation include the way the colour red acts as an unlearned releaser in male sticklebacks for aggressive behaviour (Tinbergen 1953) 
and sexual approach towards females (Rowland et al. 1995), the primary incentive effects of female olfactory, auditory and/or visual cues on the sexual behaviour of male rats, Rattus norvegicus (e.g. Lopez et al. 1999; Lopez \& Ettenberg 2001) and marmosets, Callithrix jacchas (Ferris et al. 2001) and the eliciting effects of visual and auditory prey stimuli on predatory behaviour in cats, Felis catus (Bradshaw 1992; Hall et al. 2002). Resource cues can also acquire motivational salience through conditioning. For example, in humans, the presence of cigarettes or beer cans, or even pictures of them, increases motivation to smoke or drink (Mucha et al. 1999; Geier et al. 2000; Glautier et al. 2001; Sayette et al. 2001). Human choices are also influenced by packaging, which can increase the amount purchased, consumer satisfaction and the degree to which the product's consumption is defended as prices rise (Deliza \& MacFie 1996; Sloman 1997).

Resource cues, in contrast, could also reduce motivation to reach resources by providing information. Gaining information about a resource can be an important reason for working for it (e.g. Herrnstein \& Loveland 1975; Inglis et al. 1997). For example, European starlings, Sturnus vulgaris, provided with free food will spend more time feeding from a lower-quality food patch if opaque screening means they cannot visually assess that patch (Bean et al. 1999). Thus, if resource cues provide free and useful information, without the need for close contact, this could reduce the motivation to interact more closely with that resource.

These two potential effects of resource cues are clearly important. First, they could enhance or decrease the test animal's motivation, affecting the validity with which we can extrapolate from it to the 'applied' situation. Second, they could affect how preferences are rank ordered, because cues are likely to be important for some resources but unimportant for others. For example, resource cues seem to have little enhancing effect on the motivation of hens, Gallus gallus domesticus, to perform the sitting phase of laying (Cooper \& Appleby 1996; Freire et al. 1996), or on the initial phase of nest building in sows, Sus scrofa (Jensen 1993), and olfactory cues seem relatively unimportant for male sexual motivation in the ram, Ovis aries (Lindsay 1965). Similarly, information per se is likely to be a more important attribute for some resources than for others. For example, information-gathering behaviour occurs more when resource availability is relatively uncertain (Inglis et al. 1997), so it may be most important for variable resources. Resources that differ in their remote assessability or cue strength could also appear to be valued differently, even if their inherent value to the animal is the same. Thus, overall, resource cues could affect what we conclude about animals' motivation.

\section{Experimental Preference Studies}

Broadly similar methods have been used in a range of animal welfare studies to determine resource importance (e.g. Dawkins 1983; Matthews \& Ladewig 1994; Bubier 1996; Sherwin \& Nicol 1996; Warburton \& Nicol 1998, 2001; Widowski \& Duncan 2000; Mason et al. 2001), in all of them, preference could have been affected by resource cues. In some studies, a degree of distance between the payment point and the resource may have prevented visual cues from impinging on the subjects, but olfactory and auditory cues were not screened (Sherwin \& Nicol 1996; Warburton \& Nicol 1998, 2001). Similarly, although Matthews \& Ladewig (1994) minimized the visual cues coming from a conspecific by shielding it from view, olfactory and auditory cues were not obscured. In many experiments, however, no attempts were made to shield subjects from cues, so it is reasonable to assume that before payment for the resource, subjects had access to visual, olfactory and possibly auditory stimuli from the test resources (e.g. Dawkins 1983; Bubier 1996; Mason et al. 2001). For example, in one study mink chose between a range of resources (e.g. swimming water, toys, novel objects), which they reached by pushing weighted access doors (Cooper \& Mason 2000, 2001; Mason et al. 2001). Because the apparatus was fairly compact and made of wire mesh, all of the resources could readily be detected. Most parts of the apparatus, including the choice point (the point at which each mink chose how hard to work for a resource), were only about $30 \mathrm{~cm}$ from each resource, and access doors were made of transparent plastic.

Our aim in this study was to use mink to investigate the importance of resource cues in preference-testing experiments, by reassessing their priorities in this typical set-up and comparing them with those displayed when resource cues were minimized.

\section{METHODS}

\section{Experimental Subjects}

We obtained eight 'Wild Type' adult female mink (a dark brown commercial colour type) from a farm population. They were kept under natural light and temperature conditions in an unheated barn, in conditions similar to those both on farms and in previous work (e.g. Mason et al. 2001). Food and water were replenished daily at 0900 hours. The food was standard farmed mink food (an offal-based paste), produced by a U.K. mink farmer.

\section{Apparatus and Test Resources}

We used two types of apparatus, one for each treatment. Each consisted of a home cage similar to a standard mink farm cage $(300 \times 600 \mathrm{~mm}$ and $450 \mathrm{~mm}$ high; Joergensen 1985), containing a nestbox and bottle of drinking water. Each home cage was attached to four resource cages (each also standard farm size) by four access tunnels, each entered via a one-way weighted door. Altering the weights on these doors thus altered the cost of resource access (Cooper \& Mason 2000, 2001; Mason et al. 2001). Access to and exit from each resource cage was via other one-way doors (unweighted), the opening of which triggered microswitch signals to a computer via an Arachnid signal input system (CeNeS Ltd, Cambridge, U.K.); these doors thus automatically recorded the animals' activity (Cooper \& Mason 2001; Mason et al. 2001). 


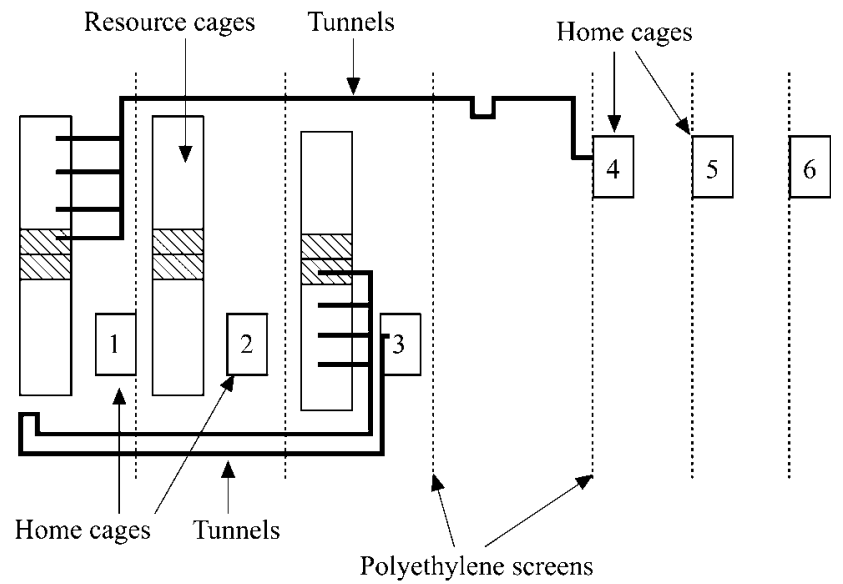

Figure 1. Diagram of the apparatus. The top half of the enclosure shows the design of the No Cues treatment, with four 7.5-m tunnels leading from the home cages $(4,5,6)$ to the four resource cages (shown for only one home cage-resource cage, and the four tunnels are not shown separately). The bottom half of the enclosure shows the design of the Cues treatment, in which the home cages $(1,2,3)$ were close to the resources at the point of payment, but the mink were still required to travel $7.5 \mathrm{~m}$ and via eight corners to reach the resource, as in the No Cues treatment. Shaded area: two adjacent resource cages for two neighbouring mink, representing the Unpredictable Social Contact resource.

Return home from each resource cage was via separate exit tunnels. Leaving a resource and returning home was always 'free' (Warburton \& Nicol 1998). Thus, overall, once a mink had left a resource, the only way back to it or to another resource was via the exit tunnel, back to the home cage, and thence via a costly access tunnel (Fig. 1).

We used the following four resources, motivation for which was assessed for each mink under both treatment conditions: (1) Food, (2) Bath, (3) Toys and (4) Unpredictable Social Contact. Food is a priority resource which we used to give us measures of peak motivation (Mason et al. 2001); it is also a resource for which internal motivational factors are likely to be as important as external ones, or even more so, (e.g. McFarland \& Houston 1981; Bell 1991), although gaining information about it may also be important (Inglis et al. 1997; Bean et al. 1999). The water bath measured $1685 \times 685 \mathrm{~mm}$ and was filled to a depth of $600 \mathrm{~mm}$; it allowed swimming, head dipping and drinking, and is thought to be a high-priority resource (Mason et al. 2001). The Toy was a red plastic ball $(16 \mathrm{~cm}$ diameter), which, from studies of cats, we hypothesized might provide cues eliciting predatory motivations (Bradshaw 1992; Hall et al. 2002). Unpredictable Social Contact was provided by allowing the mink to enter a compartment adjacent to the 'Social Contact' resource compartment of a neighbour (Fig. 1) and separated from it only by a double wall of wire mesh. Resource cues might well elicit conspecific approach, but when screened, the unpredictable nature of this resource might also make repeated checking particularly important. Six sets of apparatus were constructed, three of each treatment type.

\section{Experimental Treatments}

We assessed motivation under two treatments, designed to differ in the extent to which the mink were exposed to resource cues at the point of payment.

\section{Cues treatment}

The Cues treatment represented a typical preference test. The resources were close $(85-95 \mathrm{~cm})$ to the home cage (Fig. 1), and all apparatus walls were made of wire mesh. Thus, when in the home cage, and also when choosing which resource to work for, each mink was exposed to resource cues.

However, to control for the travel costs incurred in the second treatment (below), the mink were required to travel through $7.5 \mathrm{~m}$ of tunnel with eight corners (shown in Fig. 1) to reach each resource. Access routes and travel costs were thus identical in the Cues treatment and that described below.

\section{No cues treatment}

In the No Cues treatment, the home cage and resource compartments were separated by $7.5 \mathrm{~m}$ and by opaque (black polyethylene) screens (Fig. 1). Thus, in the home cage and at the choice point, each subject was exposed to no visual cues from the resource, along with reduced (perhaps even eliminated) olfactory and auditory cues.

\section{Experimental Trials}

We rotated the eight animals six at a time through the different sets of apparatus, so that at any one time, six were tested and two were retained in separate holding cages. The holding cages were composed of two standard mink cages connected by a tunnel, with one-way access doors into and out of each cage. One cage contained food and water and a nestbox, and the other contained toys and a small water bath. These two 'resting' mink were housed next to each other with a double wire-mesh screen between them. Within each treatment, the mink in the test apparatuses were exposed to increasing costs of access to all four resources simultaneously. Each cost, starting at $0 \mathrm{~g}$, was imposed for 1 week before being increased by $500 \mathrm{~g}$ for the next week, and so on. This imposed a cost on each visit, which could be as long as the animal's maximum bout length, or shorter if it chose to leave earlier. This procedure continued until the mink stopped paying for each resource. Finally we recorded a second 0 -g baseline to control for changes in resource use caused by order effects (e.g. habituation or motivational changes with season). This was important, because each trial took an average of 8 weeks, and some took up to 10 weeks.

\section{Measures of Motivation}

Motivation was assessed from baseline visit rates to each of the four resources when they were free, and four measures that reflected how resource use was defended in the face of increased costs. We used a range of measures, 
because each brings its own practical and interpretive difficulties (e.g. Kirkden et al. 2003); we also suspected that different measures would be differentially sensitive to cue effects. Baseline visit rate gives a measure of resource use under zero costs, allowing us to assess demand or consumption when access is free. It was used because basic demand, as well as the defence of that demand under increasing costs, can be affected by advertising stimuli (Sloman 1997). Maximum price paid was used as a measure of peak motivation (e.g. Hursh et al. 1998; Mason et al. 2001) and was defined as the maximum weight pushed before resource use was abandoned. This measure assesses the value of the first obtained unit of a resource in any session or bout (Kirkden et al. 2003), and may be influenced by deprivation effects (and thus be relatively insensitive to external cues) more than the other measures. For example, maximum price paid is one of the few economic measures that ranks water more highly than diamonds in terms of value to humans (Begg et al. 2000). We assessed consumer surplus by measuring the area under the demand curve of access price versus number of visits. This is used by economists as a measure of resource value (e.g. Ng 1990; Houston 1997; Kirkden et al. 2003), and its calculation here is based on the 'travel cost' method used by environmental economists. We calculated the entire area under the curve, which estimates the value to the consumer of receiving the resource free (e.g. Pearce \& Turner 1990; Hartwick \& Olewiler 1998). The expenditure rate was calculated as the number of visits, multiplied by the cost of access, divided by the number of weeks in the trial. Animals with a certain expenditure rate are assumed (e.g. optimality models; Stephens \& Krebs 1986; Houston 1997) to be reaping benefits at a even greater rate; this measure thus estimates the minimum rate of gain from each resource and is also less influenced by large-scale expenditure at low costs than is consumer surplus. Finally, we calculated a measure of elasticity of demand (but see Cooper \& Mason 2001) as the slope of the log-log plot of visit number versus access price (e.g. Lea 1978). Because elasticity tends to be affected by baseline consumption rate, with goods that take a large proportion of the subject's budget being inherently highly elastic (e.g. Lea 1978; Sloman 1997; Kirkden et al. 2003), we controlled for this confound by using the number of baseline visits as a covariate in all elasticity analyses.

We hypothesized that if there were no effect of cues on the motivation of the mink to reach the four resources, then there should be no difference between the two treatments in measured motivation. However, if the resource cues either had an eliciting effect on behaviour, or reduced the need for closer inspection of a particular resource, then we would expect differences between the two treatments, with these effects probably differing between the resources tested.

\section{Statistical Analysis}

Two animals became ill during different parts of the experiment, and so were left out of the final analysis owing to missing data. Data from the six remaining animals were analysed with the general linear model of Minitab 12.22 (Minitab. Inc., U.S.A.). Pre- and postexperimental baselines were compared, and averaged where there were no differences. Treatment effects were assessed with the model: Value $=$ Mink+ Resource + Treatment+Resource $\times$ Treatment+Resource $\times$ Mink+Treatment $\times$ Mink (with Mink as a random factor). For elasticity, baseline visit rate was also added as a covariate. Data were log transformed where necessary. Post hoc Tukey tests were conducted with Minitab to establish where any significant differences lay. For all tests, we used a comparisonwise $\alpha$ of 0.05 . To guard against type II error, we accepted results as biologically interesting only if more than one of the five tests showed significance and if they showed consistency across our measures of demand (Rothman 1990; Proschan \& Waclawiw 2000). We did not reduce our cutoff for $\alpha$, because our small sample size already gave us a high risk of type I error (Sankoh et al. 1997).

\section{Ethical Note}

At high costs the mink were monitored carefully and once they stopped paying for food for $23 \mathrm{~h}$, we stopped the trial and provided the food for free. U.K. Home Office guidelines state that a licence is not required for food deprivation under $24 \mathrm{~h}$, for animals weighing $100 \mathrm{~g}$ or more (female mink weigh about $800 \mathrm{~g}$ ). Laboratory studies also show that (1) mink fasted for 2 days retain full control of renal water and electrolyte metabolism (Wamberg et al. 1996), (2) 24-h fasting does not cause stomach ulceration (Harri et al. 1995), and (3) weekly 24-h fasts are normal practice on some U.K. fur farms (Mason 1993). However, there is little doubt that using food as a resource in this way made the animals hungry, and 'starve days' have recently been proscribed on farms. Thus, using maximum price paid with food as a test resource raises ethical issues not raised by other measures of preference.

\section{RESULTS}

\section{Baseline Visit Rates}

Pre- and postexperimental visit rates, when the access cost was zero, did not differ for any resource $\left(F_{1,95}=0.41\right.$, $P=0.55)$ and we therefore used the average of these visit rates.

Mean baseline visit rates differed between resources $\left(F_{3,47}=3.91, P=0.03\right)$ and were affected by a resource $\times$ treatment interaction $\left(F_{3,47}=3.89, P=0.031\right)$. In the Cues treatment, the rank order of visit rates was Social $>$ Food $>$ Toy $>$ Bath, although none of these differences between resources was significant. In the No Cues treatment, the rank order of visit rates changed to Food $>$ Bath $>$ Social $>$ Toy, and visit rates to Social and Toy were now significantly lower than those to Food $\left(T_{5}=3.708, \quad P=0.013 ; T_{5}=4.571, P=0.001\right.$, respectively; Fig. 2a). 

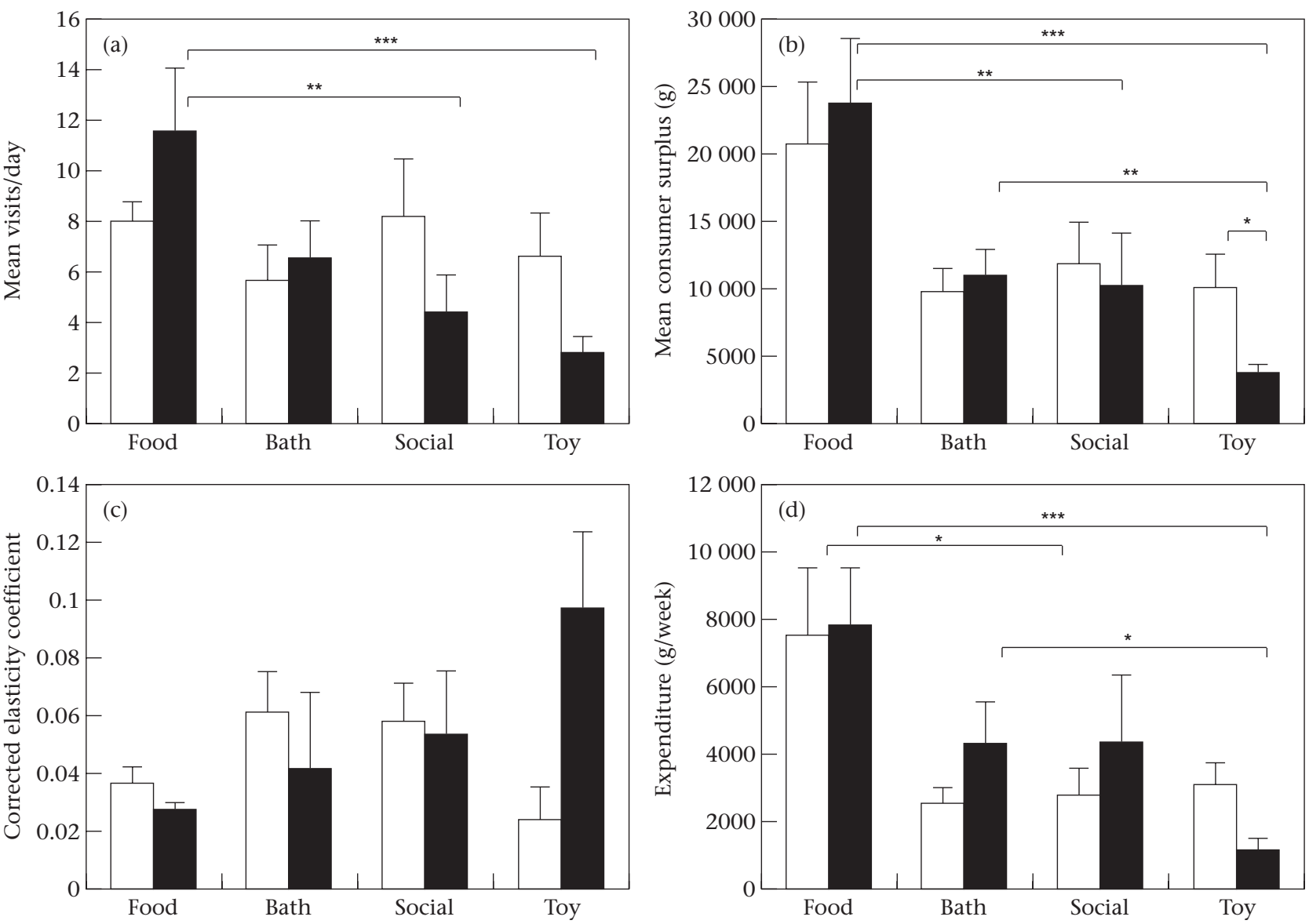

Figure 2. (a) Baseline visits, (b) travel cost consumer surplus, (c) elasticity corrected for baseline visit rate and (d) expenditure rate for each resource under the Cues $(\square)$ and the No Cues $(\square)$ treatments. Means are given + SE. ${ }^{*} P<0.1 ;{ }^{* *} P<0.05 ;{ }^{* *} P<0.001$.

\section{Maximum Price Paid}

Neither resource nor treatment significantly affected this measure.

\section{Consumer Surplus}

For consumer surplus there were no main effects, but there was a significant resource $\times$ treatment interaction $\left(F_{3,47}=3.91, P=0.03\right)$. This was caused by significant differences between Food and Social $\left(T_{5}=3.776, P<0.05\right)$, between Food and Toy $\left(T_{5}=6.299, P<0.0001\right)$ and between Bath and Toy $\left(T_{5}=3.568, P<0.05\right)$, which emerged only in the No Cues treatment (Fig. 2b). The order of preference for the resources also changed between the treatments, from Food $>$ Social $>$ Toy $>$ Bath in the Cues treatment (with no significant differences between resources in this treatment), to Food $>$ Bath $>$ Social>Toy in the No Cues treatment. Motivation for Toys was also less in the No Cues than in the Cues treatment, although not significantly so $\left(T_{5}=2.875\right.$, $P=0.1$; Fig. 2b).

\section{Visit Elasticity}

Using the model elasticity=baseline visit rate + mink + resource+treatment+resource $\times$ treatment, corrected for baseline visit rate by using it as a covariate, there were again no main effects of treatment or resource on the measure, but there was a significant resource $\times$ treatment interaction $\left(F_{3,47}=3.28, P=0.05\right)$. This result suggests that, as with the consumer surplus, treatment affected the motivation for some resources but not others (Fig. 2c). Unlike the other measures used, higher values of elasticity corresponded to lower levels of motivation. The order of preference for the resources changed between treatments, from Toy $>$ Food $>$ Bath \& Social in the Cues treatment, to Food $>$ Bath $>$ Social $>$ Toy in the No Cues treatment, although the differences between resources were nonsignificant.

\section{Expenditure Rate}

There was a similar nonsignificant trend towards a treatment $\times$ resource interaction for expenditure rate $\left(F_{3,47}=2.56, P=0.09\right)$. This was particularly influenced by differences in the expenditure rates for Food and Toy $\left(T_{5}=5.342, P<0.001\right)$, and Bath and Toy $\left(T_{5}=3.143\right.$, $P=0.056)$, which emerged only in the No Cues treatment. The rank order of preference also differed between the treatments, changing from Food $>$ Toy $>$ Social $>$ Bath in the Cues treatment, although, as for the other measures, none of these resource differences was significant, to 
Food $>$ Bath \& Social $>$ Toy in the No Cues treatment (Fig. 2d).

\section{DISCUSSION}

Overall, the results show that exposure to resource cues affected the behaviour and motivation of mink, and that it did so in different ways for different resources. The rank order of inferred preferences was thus affected by the treatment (Cues or No Cues) at the time of testing as measured by both the number of visits made when resources were free, and how behaviour changed when visits were made costly.

\section{Implications for Motivation Assessment}

We conclude that motivation to interact with resources is therefore affected by the presence of resource cues, but that different resources are affected to different extents. If rank orders of preference shift according to the presence or absence of resource cues, as we have shown, apparatus design needs to be selected with care before results are used to answer applied questions. We suggest that the best design will depend on the question being asked. To assess the welfare benefits of adding potential environmental enrichments to a cage or enclosure, testing subjects in the presence of resource cues should be most valid, because their motivation and preferences will most closely mimic those of the 'real' animal provided with that resource. Thus, if an animal is highly motivated to interact with resource $\mathrm{X}$ when $\mathrm{X}$ is near and conspicuous, $X$ is likely to be an effective environmental enrichment, even if the animal's motivation would decline if $\mathrm{X}$ were out of sight. Typical experimental designs (Dawkins 1983; Matthews \& Ladewig 1994; Bubier 1996; Sherwin \& Nicol 1996; Warburton \& Nicol 1998, 2001; Mason et al. 2001) are therefore good for addressing this sort of question, although some designs could have been more suitable had they further increased cue exposure. However, if we are instead interested in the harder issue of identifying the absent resources that animals 'need' or 'miss' most in captivity, then testing subjects without resource cues will give the most valid answer (although still only an approximation). Such experimental designs should mimic the motivations of applied subjects far better than those where resource cues are available at the point of payment. To date, however, no experiments have met these criteria.

The different measures that we used did not completely concur with one another because they each measured a different aspect of the data; the indices themselves might have been differentially sensitive to resource cues, as discussed in the Introduction. The maximum price index, for which we found no effect of treatment, is a measure of the value of the first visit to the resource per session. As such, this measure is likely to be most influenced by internal state (e.g. deprivation) and to be inherently less sensitive to external cues than are the other measures. The other indices should be more sensitive to external influences on motivation, such as eliciting cues, because they measure consumption over a large number of visits. This explanation suggests that different measures, as well as different designs, vary in their suitability for addressing the two types of applied question for which motivational data are used.

\section{Implications for Mink}

Our small sample sizes precluded much analysis as to the exact sources of the treatment $\times$ resource effects on mink motivation, because the between-treatment Tukey comparisons for each of the four resources were almost always nonsignificant. There was one exception, however: for Toys, the abolition of resource cues caused a nonsignificant trend towards reducing the minks' consumer surplus (cf. predatory behaviours of cats: Bradshaw 1992; Hall et al. 2002). This trend suggests that cues from Toys may have increased the minks' motivation to interact with them.

With larger sample sizes, we might also have found that the abolition of resource cues caused a significant reduction in motivation for Unpredictable Social Contact (especially as assessed by baseline visits and consumer surplus; Fig. 2a, b), as though eliciting stimuli were important here. With larger sample sizes, the analyses might also have shown a significant increase in the minks' motivation for Food (especially as assessed by baseline visits, consumer surplus and expenditure rate; Fig. 2a, b, c) in the No Cues treatment, as though information gain were an important component of visiting food (Inglis et al. 1997; Bean et al. 1999). Our results also suggest that resource cues might have little effect on the motivation for the water bath, as though swimming and head dipping are internally rather than externally motivated, although again larger samples would be needed to rule out the possibility of type II error. Overall, these aspects of the detailed control of mink motivation remain speculative, requiring replication with more animals.

Paradoxically, the findings from studies (e.g. Mason et al. 2001) that were conducted in typical experimental set-ups, in which cues were available at the point of preference measurement, were most closely replicated by our mink in the No Cues treatment. Thus, only when the resource cues were screened did our mink differ significantly in their responses to the four resources, replicating previous findings (Mason et al. 2001). Only then did the Bath emerge as preferred to Social, and Toys emerge as the least preferred resource. We can think of three main explanations for this. First, because the mink in this experiment came from a different population to those used in other studies, there may be population differences in the extent to which external cues affect motivation (e.g. Deliza \& MacFie 1996; Dockstader \& van der Kooy 2001; Drobes et al. 2001), with the subjects of this experiment being far more susceptible than those of previous work. Second, the resources used may have differed in the eliciting properties of their cues, with the Toy used here influencing our subjects in the Cues treatment far more than did the smaller toys used in earlier work. Third, previous experiments took far longer than 
this one (months instead of weeks for each treatment); previous subjects may thus have habituated to resource cues (e.g. the habituation of cats' predatory responses with prolonged exposure to prey cues; Leyhausen, cited in Lorenz 1981), while our subjects still found them influential.

\section{Future Work}

Future work to refine preference measurement could build on these results by removing secondary environmental cues as well as resource cues. For an animal to learn to, for example, push through different doors to reach different resources, it must associate specific contextual cues with the different rewards (e.g. Dickinson 1989), and these contextual cues may then themselves come to enhance the animal's motivation to interact with the resources. For example, the visibility of secondary cues such as cue lights reduced the impact of increasing access costs on doves, Streptopelia risoria, working for food and water (Larkin \& McFarland 1978), and secondary reward cues placed near a response manipulandum in operant studies can induce excessively high levels of instrumental responding (e.g. Tomie 1996). Secondary cues such as specific locations or arbitrary paired stimuli can also increase motivations to ingest addictive drugs in both humans and nonhuman animals (Brown \& Bowman 1995; Lu et al. 2002). In a set-up such as ours, one solution would be to construct a single corridor with just a single weighted resource access door leading to all four resources; only after preference has been expressed by payment of a cost would this diverge into resourcespecific access routes.

Such experiments would increase our knowledge of how cues affect motivation, and how this differs between motivational systems. Furthermore, although they would still not solve the problem that experience or knowledge of the resource's presence may affect motivation (Petherick et al. 1990; Juliano \& Brandon 1998), such designs might also lead to experimental paradigms better able to estimate what animals miss when it is absent from their captive environments.

\section{Acknowledgments}

Thanks to FAWRC and BBSRC for funding this research and to Catharine Clarebrough and J.M. \& M.M. for their help with animal care. Thanks also to Mike Mendl for statistical advice and to Richard Kirkden and an anonymous referee for helpful comments on the manuscript.

\section{References}

Arnold, S. J. 1981. Behavioural variations in natural populations II. The inheritance of feeding response in crosses between geographical races of the garter snake. Evolution, 35, 510-515.

Bateson, P. P. G. 1980. Optimal outbreeding and the development of sexual preferences in the Japanese quail. Zeitschrift für Tierpsychologie, 53, 231-244.
Bean, D., Mason, G. J. \& Bateson, M. 1999. Contra freeloading in starlings: testing the information hypothesis. Behaviour, 136, 10-11.

Begg, D., Fischer, S. \& Dornbusch, R. 2000. Economics. London: McGraw-Hill.

Bell, W. J. 1991. Searching Behaviour: The Behavioural Ecology of Finding Resources. Cambridge: Chapman \& Hall.

Bradshaw, J. W. 1992. The Behaviour of the Domestic Cat. Wallingford: $C A B$ International.

Brown, V. J. \& Bowman, E. M. 1995. Discriminative cues indicating reward magnitude continue to determine reaction time of rats following lesions of the nucleus accumbens. European Journal of Neuroscience, 12, 2479-2485.

Bubier, N. E. 1996. The behavioural priorities of laying hens: the effect of cost / no cost multi-choice tests on time budgets. Behavioral Processes, 37, 225-238.

Cabanac, M. 1971. Physiological role of pleasure. Science, 173, 1103.

Cabanac, M. 1979. Sensory pleasure. Quarterly Review of Biology, 54, $1-29$.

Cooper, J. J. \& Appleby, M. C. 1996. Demand for nest boxes in laying hens. Behavioural Processes, 36, 171-182.

Cooper, J. J. \& Mason, G. J. 2000. Increasing costs of access to resources cause re-scheduling of behaviour in American mink (Mustela vison): implications for the assessment of behavioural priorities. Applied Animal Behaviour Science, 66, 135-151.

Cooper, J. J. \& Mason, G. J. 2001. The use of operant technology to measure behavioral priorities in captive animals. Behavior Research Methods, Instruments and Computers, 33, 427-434.

Dawkins, M. S. 1983. Battery hens name their price: consumer demand theory and the measurement of ethological 'needs'. Animal Behaviour, 31, 1195-1205.

Dawkins, M. S. 1990. From an animal's point of view: motivation, fitness and animal welfare. Behaviour and Brain Science, 13, 1-61.

Deliza, R. \& MacFie, H. J. W. 1996. The generation of sensory expectation by external cues and its effect on sensory perception and hedonic ratings: a review. Journal of Sensory Studies, 11, 103-128.

Dickinson, A. 1989. Contemporary Animal Learning Theory. Cambridge: Cambridge University Press.

Dockstader, C. L. \& van der Kooy, D. 2001. Mouse strain differences in opiate learning are explained by differences in anxiety, not reward or learning. Journal of Neuroscience, 21, 9077-9081.

Drobes, D. J., Miller, E. J., Hillman, C. H., Bradley, M. M., Cuthbert, B. N. \& Lang, P. J. 2001. Food deprivation and emotional reactions to food cues: implication for eating disorders. Biological Psychology, 57, 153-177.

Ferris, C. F., Snowdon, C. T., King, J. A., Duong, T. Q., Ziegler, T. E., Ugurbil, K., Ludwig, R., Schultz-Darken, N. J., Wu, Z. J., Olson, D. P., Sullivan, J. M., Tannenbaum, P. L. \& Vaughan, T. J. 2001. Functional imaging of brain activity in conscious monkeys responding to sexually arousing cues. Neuroreport, 12, $2231-2236$

Forkman, B. \& Haskell, M. J. 1999. Incentive: the neglected facet of motivation. In: Proceedings of the 33rd International Congress of the International Society for Applied Ethology (Ed. by K. E. Bøe, M. Bakken \& B. Braastad), pp. 38-42. Lillefors: Agricultural University of Norway.

Freire, R., Appleby, M. C. \& Hughes, B. O. 1996. Effects of nest quality and other cues for exploration on pre-laying behaviour. Applied Animal Behaviour Science, 48, 37-46.

Geier, A., Mucha, R. F. \& Pauli, P. 2000. Appetitive nature of drug cues confirmed with physiological measures in a model using pictures of smoking. Psychopharmacology, 150, 283-291.

Glautier, S., Rigney, U. \& Willnew, P. 2001. Motivation for alcohol assessed by multiple variable schedule behaviour: effects of reward size and alcohol cues. Behavioural Pharmacology, 12, 81-89. 
Hall, S. L., Bradshaw, J. W. S. \& Robinson, I. H. 2002. Object play in cats: the role of habituation and disinhibition. Applied Animal Behaviour Science, 79, 263-271.

Harri, M., Nurminem, L. \& Filen, T. 1995. Stomach ulcer as an indicator of stress in farm mink. Acta Agriculturae Scandinavica, Section A, 45, 204-207.

Hartwick, J. M. \& Olewiler, N. D. 1998. The Economics of Natural Resource Use. Reading, Massachusetts: Addison-Wesley.

Herrnstein, R. J. \& Loveland, D. H. 1975. Maximising and matching on concurrent ratio schedules. Journal of the Experimental Analysis of Behavior, 24, 107-116.

Houston, A. I. 1997. Demand curves and welfare. Animal Behaviour, 53, 983-990.

Hursh, S. R., Raslear, T. G., Shurtleff, D., Bauman, R. \& Simmons, L. 1998. A cost-benefit analysis of demand for food. Journal of the Experimental Analysis of Behaviour, 50, 419-440.

Inglis, I. R., Forkman, B. \& Lazarus, J. 1997. Free food or earned food? A review and fuzzy model of contra freeloading. Animal Behaviour, 53, 1171-1191.

Jensen, P. 1993. Nest building in domestic sows: the role of external stimuli. Animal Behaviour, 45, 351-358.

Joergensen, G. 1985. Mink Production. Hilleroed: Scientifur.

Juliano, L. M. \& Brandon, T. H. 1998. Reactivity to instructed smoking availability and environmental cues: evidence with urge and reaction time. Experimental and Clinical Psychopharmacology, 6, 45-53.

Kirkden, R. D., Broom, D. M. \& Edwards, J. S. S. 2003. A critical comparison of the consumer surplus and the elasticities of demand as measures of motivational strength. Animal Behaviour, 65, 157-178.

Larkin, S. \& McFarland, D. 1978. The cost of changing from one activity to another. Animal Behaviour, 26, 1237-1246.

Lea, S. E. G. 1978. The psychology and economics of demand. Psychological Bulletin, 85, 441-446.

Lindsay, D. R. 1965. The importance of olfactory stimuli in the mating behaviour of the ram. Animal Behaviour, 13, 75-78.

Lopez, H. H. \& Ettenberg, A. 2001. Dopamine antagonism attenuates the unconditioned incentive value of estrous female cues. Pharmacology, Biochemistry and Behavior, 68, 411-416.

Lopez, H. H., Olster, D. H. \& Ettenberg, A. 1999. Sexual motivation in the male rat: the role of primary incentives and copulatory experience. Hormones and Behavior, 36, 176-185.

Lorenz, K. 1981. The Foundations of Ethology. New York: SpringerVerlag.

Lu, L., Xu, N. J., Ge, X., Yue, W., Su, W. J., Pei, G. \& Ma, L. 2002. Reactivation of morphone conditioned place preference by drug priming: role of environmental cues and sensitisation. Psychopharmacology, 159, 125-132.

McFarland, D. J. \& Houston, A. I. 1981. Quantitative Ethology: the State-Space Approach. London: Pitman.

Mason, G. J. 1993. Age and context affect the stereotypies of caged mink. Behaviour, 127, 191-230.

Mason, G., McFarland, D. \& Garner, J. 1998. A demanding task: using economic techniques to assess animal priorities. Animal Behaviour, 55, 1071-1075.

Mason, G. J., Cooper, J. \& Clarebrough, C. 2001. Frustrations of fur-farmed mink. Nature, 410, 35.

Matthews, L. R. \& Ladewig, J. 1994. Environmental requirements of pigs measured by behavioural demand functions. Animal Behaviour, 47, 713-719.
Mendl, M. 2001. Animal husbandry: assessing the welfare state. Nature, 410, 31-32.

Mucha, R. F., Geier, A. \& Pauli, P. 1999. Modulation of craving by cues having differential overlap with pharmacological effect: evidence for cue approach in smokers and social drinkers. Psychopharmacology, 147, 306-313.

$\mathrm{Ng}, \mathrm{Y}-\mathrm{K} .1990$. The case for and difficulties in using 'demand areas' to measure changes in well-being. Behavioral and Brain Sciences, 13, 30-31.

Pearce, D. W. \& Turner, R. K. 1990. Economics of Natural Resources and the Environment. New York: Harvester Wheatsheaf.

Petherick, J. C., Waddington, D. \& Duncan, I. J. H. 1990. Learning to gain access to a foraging and dustbathing substrate by domestic fowl: is 'out of sight out of mind?' Behavioural Processes, 22, 213-226.

Petrie, M., Halliday, T. \& Saunders, C. 1991. Peahens prefer peacocks with elaborate trains. Animal Behaviour, 41, 323-331.

Proschan, M. A. \& Waclawiw, M. A. 2000. Practical guidelines for multiplicity adjustments in clinical trials. Controlled Clinical Trials, 21, 527-539.

Rolls, E. 1999. The Brain and Emotion. Oxford: Oxford University Press.

Rothman, K. J. 1990. No adjustments are needed for multiple comparisons. Epidemiology, 1, 43-46.

Rowland, W. J., Bolyard, K. J., Jenkins, J. J. \& Fowler, J. 1995. Video playback experiments on stickleback mate choice: female motivation and attentiveness to male colour cues. Animal Behaviour, 49, 1559-1567.

Sankoh, A. J., Hugue, M. F. \& Dubey, S. D. 1997. Some comments on frequently used multiple endpoint adjustment methods in clinical trials. Statistics in Medicine, 16, 2529-2542.

Sayette, M. A., Martin, C. S., Wertz, J. M., Shiffman, S. \& Perrott, M. A. 2001. A multi-dimensional analysis of cue-elicited craving in heavy smokers and tobacco chippers. Addiction, 96, 1419-1432.

Sherwin, C. M. \& Nicol, C. J. 1996. Reorganization of behaviour in laboratory mice, Mus musculus, with varying cost of access to resources. Animal Behaviour, 51, 1087-1093.

Sloman, S. 1997. Economics. London: Prentice Hall.

Stephens, D. W. \& Krebs, J. R. 1986. Foraging Theory. Princeton, New Jersey: Princeton University Press.

Tinbergen, N. 1953. The Herring Gull's World. London: Collins.

Tomie, A. 1996. Locating reward cue at response manipulandum (CAM) induces symptoms of drug abuse. Neuroscience and Biobehavioral Review, 20, 505.

Wamberg, S., Tauson, A. H. \& Elnif, J. 1996. Effects of feeding and short-term fasting on water and electrolyte turnover in female mink (Mustela vison). British Journal of Nutrition, 76, 711-725.

Warburton, H. J. \& Nicol, C. J. 1998. Position of operant costs affects visits to resources by laboratory mice, Mus musculus. Animal Behaviour, 55, 1325-1333.

Warburton, H. J. \& Nicol, C. J. 2001. The relationship between behavioural priorities and animal welfare: a test using laboratory mice, Mus musculus. Acta Agriculturae Scandinavica, Section A, Supplement, 30, 124-131.

Widowski, T. \& Duncan, I. J. H. 2000. Working for a dustbath: are hens increasing pleasure rather than reducing suffering? Applied Animal Behaviour Science, 68, 39-53. 